de familia. Sordo como tapia fué su sobrino el escritor don Manuel Blanco Cuartín y esta lamentable dolencia padeció igualmente el hijo de éste, el distinguido hombre público don Ventura Blanco Viel.

El historiador anónimo lleva su crueldad hasta la irreverencia, hasta el punto de convertirse casi en un detractor del marino. ¿Qué fortuna guió siempre a este hombre, se pregunta, que a mi juicio no tuvo grandes méritos? Sin embargo, hasta tiene estatua en Valparaíso y un alto renombre. Nunca ha habido un escritor que haya reducido a este hombre a sus verdaderas proporciones. Pero no todo es juicio airado y opinión apasionada en el historiador anónimo. También es sensible a la admiración y discierne el incienso de su elogio con una sutil ironía. Le reconozco al general Blanco Encalada-termina su semblanza-una gran cualidad: supo administrar muy bien su fortuna. Dicen que compró una parte de Santiago que se llamaba «Los Monos», y que muy pocos años después esta propiedad valía mucho, muchísimo más. Compró a los padres de la Merced en 8.000 pesos un fundo en Chimbarongo, y pocos años después valía cientos de miles de pesos.

¿Qué espíritu curioso y zahorí se oculta tras el escritor anónimo? Pues no sólo la pasión de la verdad es la que mueve su pluma inquieta; todo cuanto dice relación con nuestro pasado le preocupa: la autenticidad del acta del Cabildo del 18 de Septiembre de 1810 y la nueva división territorial de la República, las deficiencias de la cartografía y la insuficiencia de los textos. ¿Debemos juzgar sus líneas como desahogos del despecho, o como una formal tentativa de reacción contra la historia oficial y palabrera, hueca de sinceridad y pletórica de suficiencia y pedantería? El sarcástico e irreverente espíritu del inmortal abate Coignard parece animar su pluma mordaz, acerada y escéptica, con ese inteligente escepticismo que es la sal del pensamiento.- $\mathrm{R}$ I C A R D O D O N O S O.

\title{
En la isla del Farallón
}

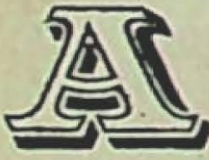

las cuatro de la mañana el mar oscuro se ilumina por arriba con las estrellas; se ilumina por el fondo con las fosforescencias que emergen al roce de la barca y perduran en la cinta de luz pálida que va trazando en sú curso la quilla. Encogidos por el frío del viento nocturno avanzamos como quien penetra en sombras, eludiendo con la 
mano segura del timonel las densas masas de las montañas y los islotes y los endebles costados de la embarcación; todo reposa en su seno, la vida interior de los peces, la indiferente gravedad de las piedras $y$ el destino de los hombres que andan en barcos.

Lo primero que en la mañana se ve del mar es la espuma; después se dibuja el horizonte, y por la costa las montañas adquieren perfiles. Abajo, late el elemento móvil, inquieto siempre, como una respiración milenaria, como un cataclismo que atesora potencia en sus pausas. El amanecer pone ojeras en el rostro y claridades en el alma. El barco pequeño camina, avanza impelido por el motor; las olas lo alzan, lo hunden, parece que juegan con él y, sin embargo, los barcos llegan a su fin. Distante, muy distante, como una piedra en medio del ancho mar, se mira el islote del Farallón; especie de faro, faro sin linternas. Ni una vida humana, ni la lámpara que siempre acompaña al hombre. Muy lejos del puerto, a muchas leguas del puerto, las corrientes levantan olas altas que se estrellan por todos los costados del peñasco hirsuto del Farallón.

Cuando el barco se acerca, da miedo acercarse: diríase que el peñasco tiene atracción y que, por magia irresistible, sobre él van a estrellarse todos los barcos. Por el frente que mira al Poniente, por el lado del océano, el islote tiene una fachada; un gran arco de caverna remeda la puerta de una enorme catedral, y a distancia, los tres o cuatro picachos del lado izquierdo fingen columnatas destruidas; el peñón entero parece entonces la extraña pirámide trunca de algún olvidado dios del Pacífico.

Las focas estaban dormidas cuando nos acercamos al islote; pero el lobo mayor que hace de centinela nos vió y comenzó a lanzar sus aullidos; algunas se despertaron; otras, las más pequeñas, siguieron recostadas entre las piedras. De pronto, al dar un rodeo frente a una pequeña ensenada, aparecieron sobre la orilla a centenares; de nuestra barca se desprendió un bote que al acercarse a tierra levantó un coro de alaridos ridículos. Pero había algo imponente en aquella soledad que se rompía, ya que no en el peligro de animales casi inermes que mata a palos el cazador. El peñasco de cerca se ve imponente, hecho todo de cantiles gigantescos, sin una playa, sin una escala; sólo una que otra cueva pedregosa y cerrada casi por la marea. Costas carcomidas, sin un paso para el desembarco, parece que el granito veteado de coloraciones duras, blanqueado por los residuos de las aves, rechaza toda invasión y repele a los mismos vientos que pasan, se alternan, rugen o se aquietan desde hace millares de años. 
Una infinita voluptuosidad de soledad; la más profunda de todas las voluptuosidades, la voluptuosidad de la soledad. Soledad de abismo. Soledad limpia, del peñón desierto desde hace miles de años, en medio del solitario océano Pacífico. Limpio el mar, sin más vida que la de los peces, limpio de huella humana. Se diría que todo el planeta está hecho para los peces y para las aves de la costa.

Y el hombre es apenas una frágil variedad que sólo se mantiene a lo largo de los ríos; una especie de sub-producto de aluvión. Sin tierra y ríos no se hubiese formado el barro de pantano de donde surge la vida de las especies terrenas. Mucho más antigua y más natural y más firme es la vida de las especies acuáticas; en primer lugar es una vida sin objeto, tal y como la naturaleza que la abriga; en seguida no tiene necesidad de ningún género de artificio para subsistir. El instinto, la inteligencia, plagas de la tierra, apenas se hacen sentir en el mar, donde una vida casi insensible mantiene sin protestas la regla de que el pez grande se come al chico, a pesar de lo cual, los débiles pululan dichosos; ejemplo, las sardinas. Y como no ha aparecido el pecado de la individualidad, unos comen y otros son comidos sin animosidad y sin tragedia.

Por uno de los ángulos del bloque de granito, en medio de las aguas, lavada periódicamente por las olas, hay una meseta de roca donde acuden a sentarse las focas más grandes. El sol bruñó con su mismo resplandor la roca lavada y la piel húmeda y lustrosa de enormes monstruos que fingen estatuas, ya recostados con muella pesantez, ya erguidos en sinuosa gallardía. La bestia mala que se acerca en los barcos se deja llevar de su idiosincrasia, toma el rifle y apunta un tiro a las paletas, buscando el sitio del corazón; estalla el sonido en el silencio de siglos y la foca brinca en el aire mal herida, se pierde después en el oleaje insondable. Y el mar profundo, profundo, se pone negro, perenne de tinta donde lo tapa alguna sombra. En cambio, donde pega el sol, es posible sondear con la mirada y se descubren peces grandes y pequeños. Uno pasa casi a flor de agua; es sólo una boca; una arrugada cavidad muscular que al volverse descubre en el lomo un collar como de ópalos dorados; se hunde, se aleja, envuelto en luz propia. Los hilos de pescar van cumpliendo su objeto, y la barca empieza a verse llena de pargos y peces menores, lustrosos, plateados, rojizos, dorados; unos minutos de estertor y en seguida la mansedumbre. Y los ojos mortecinos parecen piedras de colores que cambian de tono con el sol; he allí muchas muertes que tienen la belleza y la limpieza de la mera reacción química. Sin dolor y 
sin amor, sin pasión. La vil especie ambigua del cetáceo, en cambio, grita en la isla, alarmada por los palos de los marineros y por los disparos; aulla y se arroja al mar. Por enfrente de la barca pasan docenas de lobos sacando la cabecilla sin genio, hundiéndola para mostrar el lomo indefenso; impotentes, ruidosos, sin la inocente serenidad de los peces; sin pico ni garra; ni astucia ni ingenio. El talento lo.traen en la piel que se eriza o se ablanda adivinando las mareas, aun después de muerta la bestia y curtida la zalea.

Cuando el viento arrecia, el mar se hincha, sube, parece que va a tragarse al islote. Así hubo una época en que el mar presumía de volver a tragarse a la tierra; pero hoy el islote se queda tranquilo; creeríase que siente el apoyo de la serranía que muy distante dibuja, sin embargo, su perfil, por la región de las nubes. El viento ruge y el mar azota; las nubes fingeñ sudarios y la noche acumula sombras; pero el peñón se está muy quieto y sólo como que se empina adivinando al sol; el sol, que ha de proyectarlo otra vez victorioso en medio del cambio. Cada aurora y cada atardecer, el peñón vive sus horas solemnes de templo. Y del gran desierto nace un canto sin voz y sin notas. A medio día se disuelve el alma y en la noche profunda se acongoja y se amortaja. Pero todo esto durará lo que dure el sol y el sol también tiene que acabarse. Y nada es eterno, ni la inquietud del mar-irritante, pueril movilidad-, ni la imponente inmovilidad del peñón batido. Nada es eterno; todo se alza y se derrumba, por los siglos de los siglos, sin remedio y sin objeto. Torpe naturaleza sin plan.

Cuando la noche pone quietud en el mar; cuando el viento acaba de barrer la tierra y ha logrado alisar las aguas, entonces parece que del seno profundo nacen los cielos; nacen de las aguas; se derraman sobre la tierra y todos los pequeños prodigios se acallan delante del supremo prodigio de las estrellas.

En la gran noche lunar el peñón parece un aerolito todavía luminoso, acabado de caer. ¡Que hermoso ha de haber sido cuando era todo de fuego, sin una sola inmunda foca pegada al costado! Una estrella caída en el mar. Pero se enfrió y se ha ido pudriendo, como se pudre la vida. Y ahora lo cubren con sus desechos los pájaros y el viento lo corroe y le pinta vetas y le cava arrugas. Dan ganas de volver a encender el peñón para que se libre de plagas, para que torne a ser luz. Como un pedazo de sol caído en el mar.

¡Noches desiertas, días sin vida del Farallón; agua limpia y piedra bruñida y en torno, una vasta, una infinita soledad que llena de reposo las almas...!-J OS É V A S O N E L O S Exclusivo para Atenea en Chile. 